\title{
Schistosoma mansoni-related periportal fibrosis; can we use APRI and PSDR levels in the real-time selection of patients for targeted endoscopy in a resource-limited setting? A case-control study
}

Daniel W. Gunda ( $\nabla$ daniel_rev2002@yahoo.com)

Catholic University of Health and Allied Sciences https://orcid.org/0000-0002-2701-9321

Elizabeth F. Mtui

Catholic University of Health and Allied Sciences

Paulina M. Manyiri

Bugando Medical Centre

David C. Majinge

Bugando Medical Centre

Semvua B. Kilonzo

Catholic University of Health and Allied Sciences

Humphrey D. Mazigo

Catholic University of Health and Allied Sciences

Benson R. Kidenya

Catholic University of Health and Allied Sciences

Research article

Keywords: Schistosoma mansoni, Periportal fibrosis, esophageal varices, APRI levels, PSDR levels Hepatitis B co-infection, Northwestern Tanzania, resource-limited setting

Posted Date: September 15th, 2020

DOl: https://doi.org/10.21203/rs.3.rs-20359/v2

License: (c) (1) This work is licensed under a Creative Commons Attribution 4.0 International License.

Read Full License

Version of Record: A version of this preprint was published at BMC Gastroenterology on May 13th, 2021. See the published version at https://doi.org/10.1186/s12876-021-01802-9. 


\section{Abstract}

Background Schistosoma mansoni related hepatic fibrosis is usually associated with hemodynamic alteration with increased mortality due to bleeding varices. The diagnosis of varices before bleeding imposes a big challenge in resource-limited countries using endoscopy. Published evidence on the utility of non-invasive clinical tools in predicting the presence of varices among patients with $S$. mansoni related periportal fibrosis is still inadequate including Aspartate to platelet ratio index (APRI) and Platelet to splenic diameter ratio (PSDR) levels. This study describes the determinants of portal varices and assesses the potential utility of the APRI and PSDR level in the discrimination of portal varices among patients with $S$. mansoni related periportal fibrosis (PPF).

Methods A case-control study using cross-sectional data was done among patients with Schistosoma mansoni related periportal fibrosis at Bugando Medical Centre, in Mwanza Tanzania. Socio-demographic, laboratory, ultrasound, and upper digestive endoscopic information were collected for analysis using STATA 13. The prevalence of varices was calculated and its associated factors were determined by logistic regression. The sensitivity and specificity of independent factors were determined to assess their potential utility in discriminating the presence of portal varices in patients with PPF.

Results In total, 250 patients were included in this study, 109 (43.6\%; 95\% Cl: 37.3-.49.9) of them had varices. On multivariate analysis the odds of having varices were independently increased among patients with higher APRI levels than 1.51, (AOR: 5.8; 95\% Cl: 3.1-11.1; $p<0.001$ ) and PSDR levels that were lower than 5700 (AOR: 5.9; 95\%Cl: 3.2-11.2; $\mathrm{p}<0.001$ ). Both APRI and PSDR levels had significantly high sensitivity and specificity in predicting the presence of esophageal varices. However, the combined values of APRI and PSDR had higher specificity than any of the two markers

Conclusions This study indicates that varices are a common encounter among patients with S. mansoni related periportal fibrosis and it is independently associated with higher APRI and lower PSDR levels suggesting that these tools are potential discriminators of varices in this subgroup of patients. The reproducibility of these results should further be assessed longitudinally as potential non-invasive tools in selecting patients at high risk of having esophageal varices who could benefit from the targeted endoscopic intervention in a resource-limited setting like ours.

\section{Background}

Chronic Schistosoma mansoni infection is a common cause of morbidity and mortality in a resourcelimited setting where its transmission is ongoing. While $91.0 \%$ of the world's Schistosoma burden is found in Sub Saharan Africa (SSA), more than 54million people are infected with $S$. mansoni in this region[1]. Morbidity reports indicate that over 20 million people are chronically infected and $S$. mansoni related periportal fibrosis is reportedly the commonest and the most serious complication of chronic Schistosoma mansoni infection with high morbidity and mortality $[2,3]$. 
About 0.2 million deaths are reported annually in SSA due to complications of chronic S. mansoni infection. Heavy periportal oviposition occurs in S. mansoni infection with intense granuloma formation that ultimately graduates into periportal fibrosis (PPF), portal hypertension, and formation of esophageal varices $[4,5]$. Field-based studies indicate that close to $50.0 \%$ of people who are chronically infected with S. mansoni have periportal fibrosis and in the hospital setting more than $70.0 \%$ of patients with periportal fibrosis have been found to have attendant portal varices [6-8].

However, these patients are often diagnosed late already with fatal bleeding varices, with mortality which may be as high as $29.0 \%$ even with the best available care $[9,10]$. This is partly due to limited access to upper digestive endoscopy as a gold standard diagnostic modality in the most resource-limited setting. Endoscopy is of a maximal advantage when it is well-timed before incident bleeding [11] which would enable early identification of patients who could benefit from preventive treatment against bleeding varices and hence scale down the magnitude of subsequent mortality.

The formation of varices is linearly related to fibrosis and splenic size; but also inversely related to thrombocyte levels among others [12-15]. Out of these tests that are used in daily clinical practice some non-invasive tools have been developed including Aspartate aminotransferase (AST) to platelet count (PTC) ratio index (APRI) and Platelet to Splenic diameter ration (PSDR) levels. The APRI levels have been used to assess the severity of fibrosis in patients with PPF with excellent sonographic and histological correlation $[16,17]$, however, there is still a paucity of studies describing the utility of APRI levels in the prediction of varices in patients with periportal fibrosis. The data on the use of PSDR levels in discriminating presence of portal varices among patients with periportal fibrosis is still scarce as well when compared to patients with liver cirrhosis $[12,13,18]$.

This study was designed to assess the utility of the APRI and PSDR levels in the prediction of varices among patients with periportal fibrosis in a Schistosoma endemic area of Tanzania. This information is clinically important in maximizing the sorting-out of patients at high risk of having varices and who could benefit from further interventions to mitigate the impact of late diagnosis.

\section{Material And Methods}

A case-control study using cross-sectional data was done among patients with PPF between 2015 and 2019 at Bugando Medical Centre (BMC). A minimum sample size of 207 patients was estimated from the Lisle-Kish formula for cross-sectional studies, assuming $16.0 \%$ of patients with PPF had varices [19] with an allowable error of 0.05 at $95 \%$ confidence interval $(\mathrm{Cl})$. The diagnosis of PPF was made sonographically as done previously [20], after informed consent. Seriously ill and pregnant patients were excluded. Sonographically, details on portal vein diameter (PVD), splenic diameters (SPD), and the presence of ascites were documented. All participants also underwent a test for active $S$. mansoni infection either by Urine Circulating Cathodic Antigen (CCA) or stool Kato Katz (KK). Hepatitis B surface antigen (HBsAg), liver injury (AST and ALT), and Complete blood count (CBC) was also done among others. Finally, all patients underwent upper digestive endoscopy to assess the presence of esophageal 
varices, praziquantel (PZQ) was given twice a year, Propranolol was added if they participants had small varices and band ligation for those with large varices.

Patients with PPF were serially enrolled until the sample size was reached. The information on research interest including patients' socio-demographic data, clinical presentation like abdominal distension, hematemesis, and melaena, ultrasound (UTS) details; test results for Schistosoma mansoni, CBC, AST, ALT, serum Albumin (ALB), and upper digestive endoscopy results were included in analysis. Data were computerized using Epi data version 3.1 (Epidata DK. Denmark, EpiData Association) and STATA version 13 (Stata Corp LP, college station, TX) was used for analysis. Continuous variables were summarized as medians with interquartile range (IQR) and categorical variables as proportions with percentages.

Aspartate (AST) to platelet count (PTC) ratio index (APRI) and Platelet (PTC) to splenic diameter (SPD) were calculated as done previously [21,22]. The presence of varices was expressed as a percentage with 95\% Confidence Interval $(\mathrm{Cl})$ and its correlates were assessed. Based on earlier data and our own experience, socio-demographic factors, level of fibrosis (APRI values), markers of decompensation (ascites, serum albumin), and platelet to splenic diameter ratio (PSDR) [4, 12, 13, 23-25] were assessed for the association. The odds ratio $(\mathrm{OR})$ with $95 \% \mathrm{Cl}$ was calculated by logistic regression to assess the degree of association between the various factors and the presence of esophageal varices. Factors with $p<0.2$ on the univariate model were included in the multivariate model and the level of significance were set at $p<0.05$.

The goodness of fit for the final model was assessed subsequently [26]. The sensitivity and specificity of independent factors in the final model were also assessed to determine their discriminative ability including the APRI levels, PSDR levels, and a combined APRI and PSDR value. The Receiver Operating Characteristic (ROC) curves were used according to Hanley and McNeil's method to determine the cut points with the best sensitivity and specificity for continuous variables which were reported as proportions with $95 \% \mathrm{Cl}$ [27].

\section{Ethical Clearance}

The permission to conduct and publish the findings from this study was sought from the Catholic University of Health And Allied Sciences (CUHAS)/BMC joint ethical committee with an ethical clearance certificate number $907 / 2019$. The patients' information was handled by the researcher alone and their identifiers including names and registration numbers were not included in the final analysis to further conserve confidentiality.

\section{Results}

\section{General study characteristics among 250 participants with periportal fibrosis}

A total of 250 participants were analyzed, males made the majority, $180(72.0 \% ; 95 \% \mathrm{Cl}$ : $65.9-77.5)$ with a male to female ratio of 2.6: 1. The median age was 41 (IQR: 33-51) years and most of them, 215 (86.0\%; 
95\%Cl: 81.1-90.1) were married. In total, 222 (88.8\%; IQR: 84.2-92.4) participants had a positive test for $S$. mansoni and 44 (17.6\%; IQR: 13.1-22.9) tested positive for hepatitis B. Ascites was found in 155 (62.0\%; 95\% Cl: 55.7-68.0) participants, and both dilated portal veins and splenomegaly were common with median measurements in centimeters of 1.5 (IQR: 1.4-1.9) and 17 (IQR: 15-18) respectively (Table 1).

Table 1: General study characteristics among 250 participants with periportal fibrosis

\begin{tabular}{|c|c|c|}
\hline Variable & Frequency & Percentage (95\%CI), Median (IQR) \\
\hline \multicolumn{3}{|l|}{ SEX } \\
\hline Male & 180 & $72.0(65.9-77.5)$ \\
\hline Female & 70 & $28.0(22.5-34.1)$ \\
\hline Age (Years) & 250 & $41[33-51]$ \\
\hline \multicolumn{3}{|l|}{ Married } \\
\hline Yes & 215 & $86.0(81.1-90.1)$ \\
\hline No & 35 & $14.0(10.0-18.9)$ \\
\hline \multicolumn{3}{|l|}{ Laboratory } \\
\hline $\mathrm{AST}(\mathrm{U} / \mathrm{L})$ & 250 & $39.8[34-56]$ \\
\hline ALT(U/L) & 250 & $32.5[19-54]$ \\
\hline $\mathrm{PTC}\left(* 10^{\wedge} 3 / \mu \mathrm{L}\right)$ & 250 & 99 [70-158] \\
\hline S. mansoni + & 222 & $88.8(84.2-92.4)$ \\
\hline $\mathrm{HBsAg}+$ & 44 & $17.6(13.1-22.9)$ \\
\hline \multicolumn{3}{|l|}{ UTS abdomen } \\
\hline Ascites & 155 & $62.0(55.7-68.0)$ \\
\hline PVD (cm) & 250 & $1.5[1.4-1.7]$ \\
\hline $\mathrm{SPD}(\mathrm{cm})$ & 250 & $17[15-18]$ \\
\hline \multicolumn{3}{|l|}{ Endoscopy results } \\
\hline Varices present & 109 & $43.6(37.4-49.9)$ \\
\hline Varices absent & 141 & $56.3(5.0-62.6)$ \\
\hline
\end{tabular}

ALT: alanine aminotransferase; AST: aspartate aminotransferase; HGB: hemoglobin; HBV: hepatitis B Virus; IQR: interquartile range; PTC: platelet counts; PVD: portal vein diameter; SPD: Splenic diameter

\section{Prevalence and prediction of varices among 250 participants with periportal fibrosis}

In this study, a total of 109 (43.6\%; 95\%Cl: 37.3-.49.9) participants were found to have esophageal varices. The distribution of varices by APRI levels indicated that APRI levels were positively correlated to 
the development of varices (table 2) where patients with esophageal varices were more likely to have higher APRI levels (Figure 1\&3) as compared to their variceal negative counterparts. The PSDR levels, on the other hand, were inversely related to the presence of portal varices (Figure 2\&3). On the multivariate model the odds of having varices were independently increased among patients with higher APRI levels than 15.1, (AOR: $5.8 ; 95 \% \mathrm{Cl}: 3.1-11.1 ; \mathrm{p}=<0.001$ ) and PSDR levels that were lower than 5700 (AOR: 5.9; $95 \% \mathrm{Cl}: 3.2-11.2 ; \mathrm{p}<0.001)$. Actives $S$. mansoni and having ascites had a non-significant positive association with the presence of varices with $p$-value $>0.05$ (Table 3 ).

Table 2: Distribution of esophageal varices by APRI levels among 250 participants with PPF

\begin{tabular}{|c|c|c|c|}
\hline \multirow[t]{2}{*}{ Varices present } & \multicolumn{2}{|c|}{ Aspartate aminotransferase to platelet ratio index } & \multirow[t]{2}{*}{ Total (n, \%) } \\
\hline & $\leq 1.5(\mathrm{n}, \%)$ & $>1.5(\mathrm{n}, \%)$ & \\
\hline No $(n, \%)$ & $113(80.1)$ & $28(19.9)$ & $141(100.0)$ \\
\hline Yes $(n, \%)$ & $19(17.4)$ & $90(82.6)$ & $109(100.0)$ \\
\hline Total $(n, \%)$ & $132(52.8)$ & $118(47.2)$ & $250(100.0)$ \\
\hline & hi2 $(1)=97$ & 001 & \\
\hline
\end{tabular}

APRI: aspartate aminotransferase platelet ratio index; CI: confidence interval; OR: odds ratio, n: number

Tab 3: Factors associated with varices among 250 patients with periportal fibrosis 


\begin{tabular}{|c|c|c|c|c|c|c|}
\hline \multirow[t]{2}{*}{ Variable } & \multicolumn{2}{|c|}{$\begin{array}{c}\text { Esophageal varices } \\
\text { present }\end{array}$} & \multicolumn{2}{|r|}{ Un adjusted } & \multicolumn{2}{|r|}{ Adjusted } \\
\hline & $\begin{array}{r}\text { No, } \\
(\mathrm{n}=141)\end{array}$ & $\begin{array}{r}\text { Yes, } \\
(\mathrm{n}=109)\end{array}$ & OR (95\%CI) & P-value & $\begin{array}{r}\text { OR } \\
(95 \% \mathrm{CI})\end{array}$ & P-value \\
\hline Age, years* & 42 [35-55] & 39 [33-47] & $0.9(0.8-1.0)$ & 0.169 & $\begin{array}{r}1.0(0.9- \\
1.01)\end{array}$ & 0.498 \\
\hline \multicolumn{7}{|l|}{ Sex } \\
\hline Female & 39 ( 27.7) & $\begin{array}{r}31 \\
(28.4)\end{array}$ & 1.0 & & & \\
\hline Male & $102(72.3)$ & 78 ( 71.6$)$ & $1.0(0.5-1.7)$ & 0.892 & & \\
\hline \multicolumn{7}{|l|}{ Married } \\
\hline No & $17(12.1)$ & 18 (16.5) & 1.0 & & & \\
\hline Yes & $124(87.9)$ & $\begin{array}{r}91 \\
(83.5)\end{array}$ & $0.7(0.3-1.4)$ & 0.316 & & \\
\hline \multicolumn{7}{|l|}{ Alcohol use } \\
\hline No & $63(44.7)$ & 64 ( 58.7) & 1.0 & & & \\
\hline Yes & 78 (55.3) & $\begin{array}{r}45( \\
41.3)\end{array}$ & $0.6(0.3-0.9)$ & 0.028 & $0.6(0.3-1.1)$ & 0.109 \\
\hline \multicolumn{7}{|l|}{$\begin{array}{l}S . \\
\text { mansoni test }\end{array}$} \\
\hline Negative & 21 (14.9) & 7 ( 6.4) & 1.0 & & & \\
\hline Positive & $120(85.1)$ & $102(93.6)$ & $2.5(1.0-6.2)$ & 0.040 & $2.4(0.9-7.0)$ & 0.095 \\
\hline \multicolumn{7}{|l|}{$\begin{array}{l}\text { Hepatitis B } \\
\text { test }\end{array}$} \\
\hline Negative & $116(82.3)$ & 90 (82.6) & 1.0 & & & \\
\hline Positive & 25 (17.7) & 19 (17.4) & $0.9(0.5-1.8)$ & 0.951 & & \\
\hline \multicolumn{7}{|l|}{ APRI levels* } \\
\hline$<1.51$ & $114(80.8)$ & \multicolumn{2}{|c|}{37 (33.9) } & 1.0 & & \\
\hline$>1.51$ & $27(19.2)$ & $72(66.1)$ & $8.2(4.6-14.6)$ & $<0.001$ & $\begin{array}{r}5.8(3.1- \\
11.1)\end{array}$ & $<0.001$ \\
\hline $\begin{array}{l}\text { PCSDR } \\
\text { levels** }\end{array}$ & & & & & & \\
\hline$>5700$ & $106(75.2)$ & 39 (26.6) & 1.0 & & & \\
\hline$\leq 5700$ & $35(24.8)$ & $80(73.4)$ & $8.3(4.7-14.7)$ & $<0.001$ & $\begin{array}{r}5.9(3.2- \\
11.2)\end{array}$ & $<0.001$ \\
\hline PVD (CM) & $1.5[1.4-$ & $1.5[1.3-$ & $0.9(0.7-1.2)$ & 0.858 & & \\
\hline
\end{tabular}




\begin{tabular}{|c|c|c|c|c|c|c|}
\hline & 1.7] & 1.7] & & & & \\
\hline SPD (CM) & $\begin{array}{r}17 \text { [15- } \\
18.3]\end{array}$ & $\begin{array}{r}17 \text { [16- } \\
18]\end{array}$ & $1.0(0.9-1.1)$ & 0.467 & & \\
\hline \multicolumn{7}{|l|}{$\begin{array}{l}\text { Ascites } \\
\text { present }\end{array}$} \\
\hline No & $62(44.0)$ & $33(30.3)$ & 1.0 & & & \\
\hline Yes & $79(56.0)$ & 76 (69.7) & $1.8(1.1-3.1)$ & 0.028 & 1. $(0.7-2.5)$ & 0.469 \\
\hline
\end{tabular}

APRI levels are positively related to variceal formation, 1.51 is the best cut point,(AUC: 0.8259); by ROC curve; *PSDR levels are inversely related, 5700 is the best cut point by ROC curve (AUC: 0.624); ALT: Alanine minotransferase; APRI: Aspartate aminotransferase-platelet index; AUC: area under the curve; HBsAg: Hepatitis 3 surface antigen; PVD: Portal vein diameter; ROC: receiver operating characteristic; SCHBCI: Schistosoma nansoni-Hepatitis B co-infection; SPD: Splenic diameter;

The assessment for the good of fitness of the final model did not demonstrate any gross lack of fit (Area under ROC curve: $0.8585 ; \mathrm{p}=0.314$ ) (figure 4). The assessment for discriminative ability indicated that higher APRI levels, (cut point: 1.51) had both higher sensitivity, (82.5\%; 95\%Cl: 74.1-89.2) and specificity (80.1\%; 95\%Cl: 72.6-86.3) as compared to PSDR levels which also had acceptably good predictive ability (sensitivity: $73.4 \%$; $95 \mathrm{Cl}$ : $64.1-81.4$; specificity: $75.2 \% 95 \% \mathrm{Cl}$ : $67.2-82.1$ ) at a cut point of 5700 in discriminating varices among patients with PPF. The combined APRI and PSDR values had a sensitivity and specificity of $54.1 \%$ (95\% Cl: $44.3-63.7)$ and $94.3 \%$ (95\% Cl: $89.1-97.5)$ respectively in predicting esophageal varices (Table 4).

Table 4: Predictive values of APRI, PSDR, and combined APRI/PSDR levels for portal varices

\begin{tabular}{|l|r|r|r|r|r|r|}
\hline Variable & ROC & Cut point & Sensitivity & 95\%CI & Specificity & 95\%CI \\
\hline APRI values & 0.8259 & 1.51 & 82.5 & $74.1-89.2$ & 80.1 & $72.6-86.3$ \\
\hline PSDR values & 0.6471 & 5700 & 73.4 & $64.1-81.4$ & 75.2 & $67.2-82.1$ \\
\hline APRI-PSDR & NA & NA & 54.1 & $44.3-63.7$ & 94.3 & $89.1-97.5$ \\
\hline
\end{tabular}

APRI: Aspartate aminotransferase-platelet index; CI: confidence interval; NA: not applicable; PSDR: Platelet splenic diameter ratio; ROC: receiver operating curve; APRI-PSDR: combined APRI and PSDR value

\section{Discussion}

The objective of this study was to determine the prevalence and correlates of esophageal varices and assess its potential discriminators among patients with $S$. mansoni related periportal fibrosis. In this study, a total of 109 (43.6\%) participants with periportal fibrosis were found to have esophageal varices, which were more likely to occur among patients with higher APRI levels and those with PSDR levels lower 
than 5700. The APRI and PSDR levels were both significantly sensitive and specific in predicting the presence of esophageal varices in this subgroup of patients.

The prevalence of varices in this study is similar to an earlier report of $45.0 \%$ from Uganda [28] and $47.0 \%$ reported from Sudan [29]. On the contrary, the prevalence of varices in this study is lower than what was reported earlier in Sudan, (43.6\% vs.67.0\%) [30] and Saudi, (43.6\% vs. $72.0 \%$ ) among patients with PPF [8]. However, the current prevalence is higher than the prevalence of $16.0 \%$ reported recently from Sudan [19]. The differences in the prevalence of varices in these studies could partly be due to the difference in the severity of liver fibrosis among studied participants since portal varices have been reported to have a linear relation with fibrosis level[14].

In this study, age, alcohol use, active S. mansoni, presence of ascites, APRI, and PSDR levels were assessed for their independent association with esophageal varices in the final model, and the prediction ability of factors with the independent association was further determined by calculating their sensitivity and specificity. Active $S$. mansoni was previously reported to have an independent association with the presence of varices in a study done by Awilly et al. among patients with upper digestive tract bleeding [31]. In our study, the presence of active $S$. mansoni infection had only a non-significant positive correlation with the presence of varices, (AOR: 2.4; IQR: 0.9-7.0; $\mathrm{P}=0.095$ ).

A positive correlation between the presence of portal varices and advanced fibrosis by ultrasound has been described previously $[4,32,33]$, in turn, some studies have reported a positive correlation between liver fibrosis determined by ultrasound with the APRI levels [16, 34]. The current finding that the portal varices in patients with PPF were independently common in patients with higher APRI levels suggests that APRI levels can be used to select patients at high risk of having varices in areas with limited services. This correlation suggests that varices develop in advanced PPF which in turn is associated with liver dysfunction and reduced thrombocyte count [35-37]. In the current study, we similarly observed a significant proportion of patients with elevated serum aspartate aminotransferase levels (ALT) and thrombocytopenia as summarized in table 1.

A combination of AST and PTC into the APRI score in this study has suggested that besides the prediction of fibrosis severity [16,34], this noninvasive tool can potentially be used in discriminating the presence of varices among patients with PPF. In this study, APRI levels had a sensitivity and specificity of 82.5 and $80.1 \%$ respectively at a cut point of 1.51 (area under ROC: 0.8259 ). The utility of this tool in predicting the presence of varices has been reported previously among patients with liver cirrhosis with results that are comparable to the findings of our current study among patients with $S$. mansoni related PPF (sensitivity: 64.7-81.5\%; specificity: 60-72.7\% [38, 39].

The evidence on the utility of PSDR in the prediction of portal varices among patients with PPF is gradually growing. In the available body of literature, PSRD has been reported to have a sensitivity and specificity of $33.3-100 \%$ and $66.0-92.0 \%$ respectively as reported by authors from Saud with sensitivity:100\% (95\%Cl: 89-100) and specificity: 92\% (95\%Cl: 62-99) [13]; China (sensitivity: $85.3 \%$ (95\%Cl:76.5-91.7\%); specificity: 83.0\%(95\% Cl:75.7-88.8\%) [25] and Sudan (sensitivity: 33.3\%; 
specificity: $66 \%$ [12]. The results of our study are consistent and falling within the reported ranges (sensitivity: 73.4\%; 95\%Cl: 64.1-81.4; specificity: 75.2\%; 95\%Cl: 67.2-82.1). Otherwise, the observed differences in the reported predictive values could partly be due to the small number of participants studied in previous studies (i.e. 43-109) and the difference in cut off points [12, 13,25].

In this study, the assessment of APRI and PSDR as a combined value in discriminating portal varices indicated that the two parameters used together significantly increase the specificity to about $95 \%$ which is higher than any of the two parameters when used alone. However, with a lower sensitivity as compared to either of the two parameters. Though this has not been reported before, these findings suggest that the combined value may potentially be useful in selecting patients with PPF who are more likely to have no varices and thus excluded from immediate endoscopic evaluation.

The current study is liable to some limitations; including the fact that this is a single-center study, its results may not be generalizable. But also there was no report of fibrosis grading by ultrasound as done in other studies, and fibrosis wasn't confirmed by liver biopsy. But also with the use of cross-sectional data, the temporal relationship between the outcome and exposure variables is difficult to ascertain. However, even with these limitations, the findings from this study are still important, especially in resource-limited settings where the burden of Schistosoma related morbidity is high with serious resource restriction.

\section{Conclusions}

This study indicates that varices are a common encounter among patients with S. mansoni related periportal fibrosis and it is independently associated with higher APRI and lower PSDR levels. The current results suggest that these tools may potentially be useful in the selection of patients at high risk of having varices for targeted endoscopic intervention in resource-limited settings. The reproducibility of these results should further be assessed longitudinally as potential non-invasive tools in selecting patients at high risk of having esophageal varices who could benefit from the targeted endoscopic intervention in a resource-limited setting like ours.

\section{Abbreviations}

ALB: albumin; ALT: alanine aminotransferase; AOR: adjusted odds ratio; AST: aspartate aminotransferase; BMC: Bugando Medical Centre; CBC: Completer Blood count; CCA: Circulating Cathodic Antigen; CUHAS: Catholic University of Health and Allied Sciences; HGB: hemoglobin; HBV: hepatitis B Virus; HBsAg: Hepatitis B surface antigen; IQR: interquartile range; KK: Kato Katz; PPF: Periportal Fibrosis; PTC: platelet counts; PVD: portal vein diameter; PZQ: praziquantel; ROC: Receiver Operating Characteristic; SCHBCl: Schistosoma mansoni-Hepatitis B co-infection; SSA: Sub Saharan Africa; SPD: Splenic diameter; UTS: ultrasound; WHO: World Health Organization

\section{Declarations}




\section{Ethical Approval and Consent to participate}

Ethical clearance was obtained with certificate no $907 / 2019$, consent to participate not applicable

\section{Consent for publication}

Not applicable

\section{Availability of supporting data}

Not applicable

\section{Competing interests}

The authors declare to have no competing interest to declare

\section{Funding}

Not applicable

\section{Authors' contributions}

DWG, HDM\& SBK: participated in designing of the study; EFM, PMM\&DCM; acquired the data; DWG\& BRK: did data analysis and interpretation; DWG: did manuscript drafting. All the authors significantly reviewed the manuscript for its intellectual content and agreed on the final version.

\section{Acknowledgment}

The authors would like to acknowledge the great support given by the department of medical records and the gastroenterology team at BMC during the retrieval of patients' information.

\section{References}

1. Adenowo, A.F., et al., Impact of human schistosomiasis in sub-Saharan Africa. Brazilian Journal of Infectious Diseases, 2015. 19(2): p. 196-205.

2. Hotez, P.J., O.A. Asojo, and A.M. Adesina, Nigeria: "Ground Zero" for the High Prevalence Neglected Tropical Diseases. 2012, Public Library of Science.

3. WHO, Schistosomiasis: Progress report 2001-2011 and Strategic plan 2012-2020. 2013: p. 74.

4. Opio, C.K., et al., Profiling lifetime episodes of upper gastrointestinal bleeding among patients from rural Sub-Saharan Africa where Schistosoma mansoni is endemic. Pan Afr Med J, 2016. 24: p. 296.

5. Gray, D.J., et al., Diagnosis and management of schistosomiasis. BMJ, 2011. 342: p. d2651. 
6. Kaatano, G.M., et al., Schistosoma mansoni-related hepatosplenic morbidity in adult population on Kome Island, Sengerema district, Tanzania. The Korean journal of parasitology, 2015. 53(5): p. 545.

7. Mueller, A., et al., Intestinal schistosomiasis of Ijinga Island, north-western Tanzania: prevalence, intensity of infection, hepatosplenic morbidities, and their associated factors. BMC infectious diseases, 2019. 19(1): p. 832.

8. Agha, A., et al., Use of the platelet count/spleen diameter ratio for the noninvasive diagnosis of esophageal varices in patients with schistosomiasis. Saudi J Gastroenterol, 2011. 17(5): p. 307-11.

9. Bessa, S. and I. Helmy, Injection sclerotherapy for esophageal varices caused by schistosomal hepatic fibrosis. Surgery, 1985. 97(2): p. 164-168.

10. El-Zayadi, A., S.S. El-Din, and S. Kabil, Endoscopic sclerotherapy versus medical treatment for bleeding esophageal varices in patients with schistosomal liver disease. Gastrointestinal Endoscopy, 1988. 34(4): p. 314-317.

11. LaBrecque, D., et al., Esophageal varices. World Gastroenterol Organ Glob Guidel, 2014. 2014: p. 114.

12. Hassan, M.A., et al., Noninvasive Prediction of Esophageal Varices Grade (Size) in Sudanese Patients with Periportal Fibrosis. Gastroenterology, 2018. 2(2): p. 28-33.

13. Agha, A., et al., Use of the platelet count/spleen diameter ratio for the noninvasive diagnosis of esophageal varices in patients with schistosomiasis. Saudi journal of gastroenterology: official journal of the Saudi Gastroenterology Association, 2011. 17(5): p. 307.

14. Richter, J., et al., Sonographic prediction of variceal bleeding in patients with liver fibrosis due to Schistosoma mansoni. Tropical Medicine \& International Health, 1998. 3(9): p. 728-735.

15. Abdel-Wahab, M.F., et al., Ultrasonographic prediction of esophageal varices in Schistosomiasis mansoni. American Journal of Gastroenterology, 1993. 88(4).

16. Derbala, M., et al., Aspartate transaminase to platelet ratio index in hepatitis $C$ virus and Schistosomiasis coinfection. World journal of gastroenterology, 2015. 21(46): p. 13132.

17. Barreto, A.V.M.S., et al., New index for the diagnosis of liver fibrosis in Schistosomiasis mansoni. Arquivos de gastroenterologia, 2017. 54(1): p. 51-56.

18. Chen, R., et al., Platelet count to spleen diameter ratio for the diagnosis of gastroesophageal varices in liver cirrhosis: a systematic review and meta-analysis. Gastroenterology research and practice, 2017. 2017. 
19. Mudawi, H., Y. Ali, and M. El Tahir, Prevalence of gastric varices and portal hypertensive gastropathy in patients with Symmers periportal fibrosis. Ann Saudi Med, 2008. 28(1): p. 42-4.

20. Richter, J., et al., Ultrasound in schistosomiasis: a practical guide to the standard use of ultrasonography for assessment of schistosomiasis-related morbidity: Second international workshop, October 22-26 1996, Niamey, Niger. 2000, Geneva: World Health Organization.

21. Chou, R. and N. Wasson, Blood tests to diagnose fibrosis or cirrhosis in patients with chronic hepatitis C virus infection: a systematic review. Annals of internal medicine, 2013. 158(11): p. 807-820.

22. Giannini, E., et al., Platelet count/spleen diameter ratio: proposal and validation of a non-invasive parameter to predict the presence of oesophageal varices in patients with liver cirrhosis. Gut, 2003. 52(8): p. $1200-1205$.

23. Madwar, M.A., et al., A prospective study: prediction of the first variceal hemorrhage in schistosomal and non-schistosomal liver disease. J Egypt Public Health Assoc, 1997. 72(3-4): p. 395-409.

24. Chofle, A.A., et al., Oesophageal varices, schistosomiasis, and mortality among patients admitted with haematemesis in Mwanza, Tanzania: a prospective cohort study. BMC Infect Dis, 2014. 14: p. 303.

25. $\mathrm{Xu}, \mathrm{X}$.-D., et al., Ratio of platelet count/spleen diameter predicted the presence of esophageal varices in patients with schistosomiasis liver cirrhosis. European journal of gastroenterology \& hepatology, 2016. 28(5): p. 588-591.

26. Fagerland, M.W., and D.W. Hosmer, A generalized Hosmer-Lemeshow goodness-of-fit test for multinomial logistic regression models. The Stata Journal, 2012. 12(3): p. 447-453.

27. Hanley, J.A. and B.J. McNeil, The meaning and use of the area under a receiver operating characteristic (ROC) curve. Radiology, 1982. 143(1): p. 29-36.

28. Ravera, M., et al., Clinical and endoscopic aspects of hepatosplenic schistosomiasis in Uganda. Eur J Gastroenterol Hepatol, 1996. 8(7): p. 693-7.

29. Kheir, M.M., et al., Effects of single-dose praziquantel on morbidity and mortality resulting from intestinal schistosomiasis. East Mediterr Health J, 2000. 6(5-6): p. 926-31.

30. Saad, A.M., et al., Oesophageal varices in a region of Sudan endemic for Schistosoma mansoni. $\mathrm{Br} \mathrm{J}$ Surg, 1991. 78(10): p. 1252-3.

31. Chofle, A.A., et al., Oesophageal varices, schistosomiasis, and mortality among patients admitted with haematemesis in Mwanza, Tanzania: a prospective cohort study. BMC infectious diseases, 2014. 14(1): p. 303. 
32. Mudawi, H., and K. Ibrahim, Endoscopic variceal sclerotherapy in patients with Symmers periportal fibroses. Tropical doctor, 2007. 37(3): p. 179-181.

33. Hassan, M.A., et al., Noninvasive Prediction of Esophageal Varices Grade (Size) in Sudanese Patients with Periportal Fibrosis. International Journal of Gastroenterology, 2018. 2(2): p. 28.

34. Lambertucci, J.R., L.C. dos Santos Silva, and C.M. Antunes, Aspartate aminotransferase to platelet ratio index and blood platelet count are good markers for fibrosis evaluation in schistosomiasis mansoni. Revista da Sociedade Brasileira de Medicina Tropical, 2007. 40(5).

35. Leite, L.A.C., et al., Hemostatic dysfunction is increased in patients with hepatosplenic schistosomiasis mansoni and advanced periportal fibrosis. PLoS neglected tropical diseases, 2013. 7(7): p. e2314.

36. Leite, L.A.C., et al., Relationship between splenomegaly and hematologic findings in patients with hepatosplenic schistosomiasis. Revista brasileira de hematologia e hemoterapia, 2013. 35(5): p. 332-336.

37. Medeiros, T.B., et al., Correlation between platelet count and both liver fibrosis and spleen diameter in patients with schistosomiasis mansoni. Arquivos de gastroenterologia, 2014. 51(1): p. 34-38.

38. Zambam de Mattos, Â., et al., Aspartate aminotransferase-to-platelet ratio index (APRI) for the noninvasive prediction of esophageal varices. Annals of hepatology, 2013. 12(5): p. 810-814.

39. Zhang, F., et al., Predictive value of a noninvasive serological hepatic fibrosis scoring system in cirrhosis combined with oesophageal varices. Canadian Journal of Gastroenterology and Hepatology, 2018. 2018.

\section{Figures}


Fig 1: Distribution of APRI levels by presence of esophageal varices among 250 participants

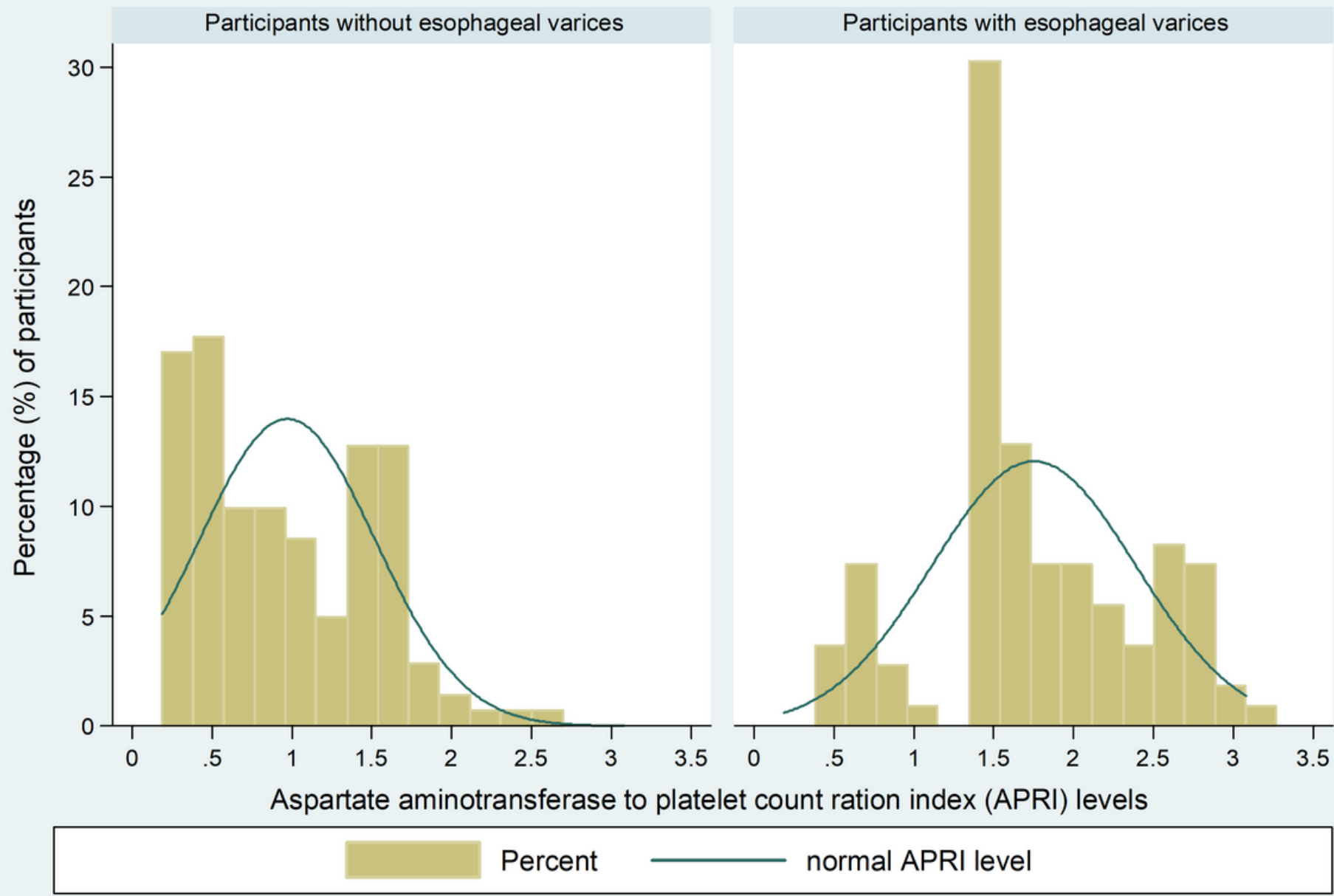

\section{Figure 1}

distribution of Aspartate aminotransferase to platelet ratio index by varices 
Fig 2: Distribution of PSDR levels by presence of varices among 250 participants

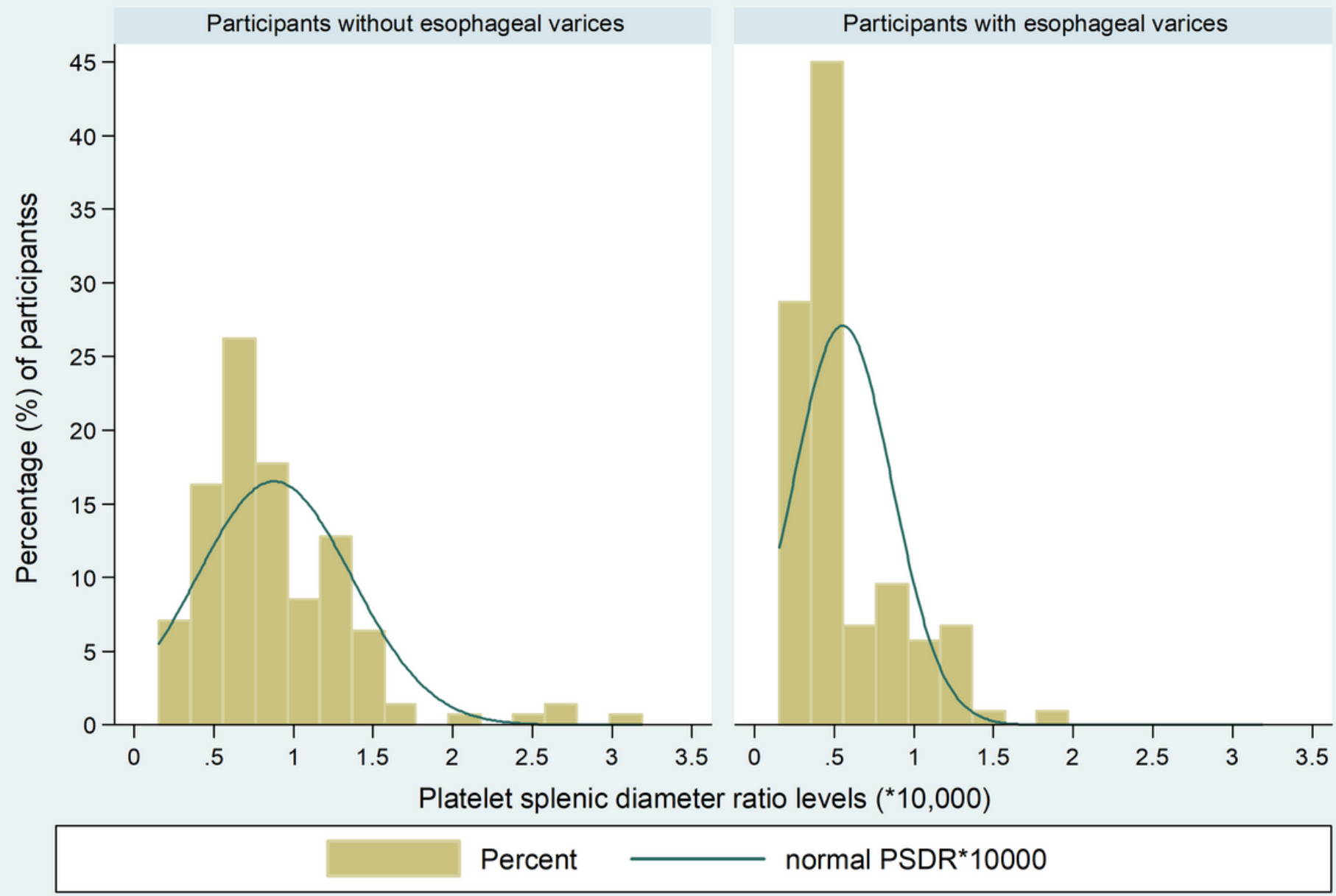

Figure 2

Distribution of Platelet to splenic diameter ratio levels by the presence of varices 
Figure: 3 Distribution of APRI and PSDR levels by presence of varices among 250 participants

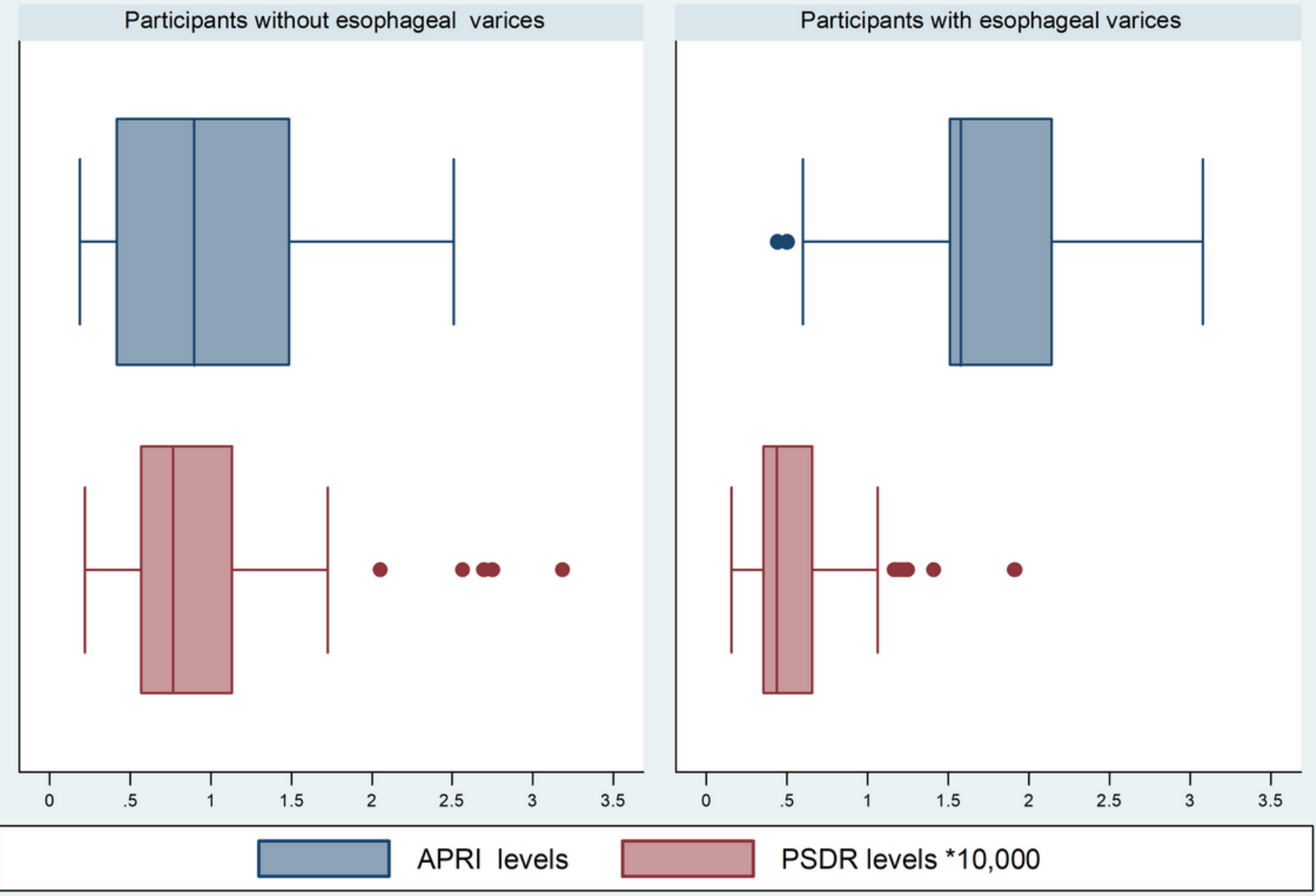

Figure 3

Box plot distribution of APRI and PSDR levels by the presence of varices 
Figure 4: Assement for goodness of fit of the final logistc model

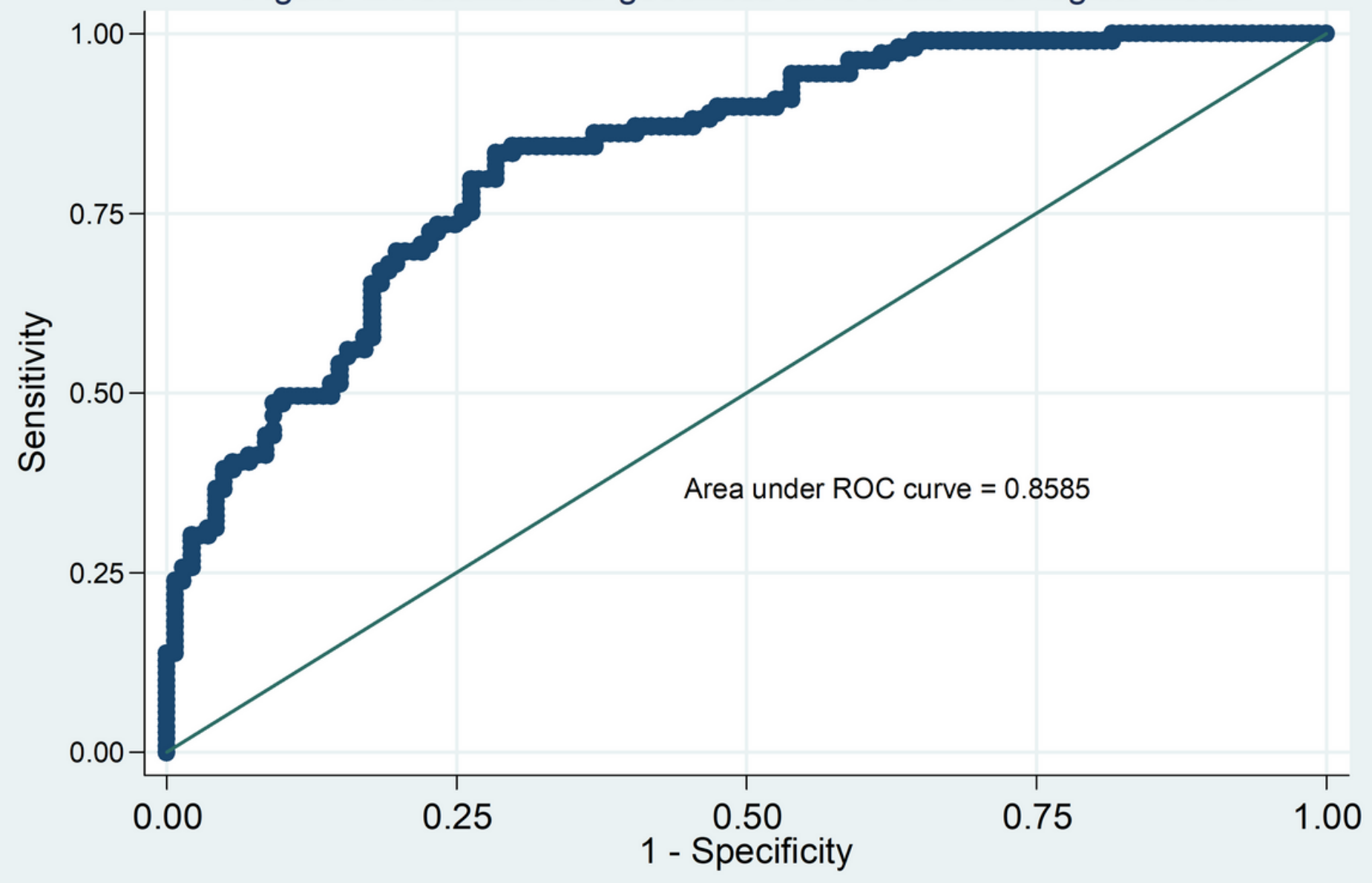

Figure 4

The goodness of fit of the final logistic model

\section{Supplementary Files}

This is a list of supplementary files associated with this preprint. Click to download.

- CSTROBEChecklistv4BMG.pdf 